\title{
Readiness to try extended-released buprenorphine and related factors of interest: comparison between incarcerated and non-incarcerated subjects with opioid use disorder.
}

Mathieu CHAPPUY ( $\sim$ mathieu.chappuy@chu-lyon.fr )

Centre Hospitalier Le Vinatier https://orcid.org/0000-0002-3176-6039

Fadi MEROUEH

Centre Hospitalier Regional Universitaire de Montpellier

Benoit TROJAK

Centre Hospitalier Universitaire de Dijon

Jérôme BACHELLIER

Centre Hospitalier Regional Universitaire de Tours

Patrick BENDIMERAD

Centre hospitalier de la Rochelle

Margaux KOSIM

Hopital Universitaire Pitie Salpetriere

Peter HJELMSTROM

Camurus

Philippe NUBUKPO

Centre Hospitalier Universitaire de Limoges

Georges BROUSSE

Centre Hospitalier Universitaire de Clermont-Ferrand

Benjamin ROLLAND

Centre Hospitalier du Vinatier

Research

Keywords: Buprenorphine, Extended-release, Opioid Use Disorder, Opioid Agonist Treatment, Patient Preferences, incarceration

Posted Date: July 21 st, 2020

DOI: https://doi.org/10.21203/rs.3.rs-43617/v1 
License: (c) (i) This work is licensed under a Creative Commons Attribution 4.0 International License. Read Full License 


\section{Abstract}

Background: Extended-release buprenorphine (XR-BUP) are new pharmaceutical products that offer a one-week-, one-month- or six-months-long buprenorphine treatment for subjects with opioid use disorder (OUD). OUD is frequent in incarcerated populations, and XR-BUP has been suggested to be an interesting treatment option in prison. However, some opioid users have deemed that XR-BUP could constitute a threat to the individual freedom of occasionally using drugs, and was also at risk to be coercively used in some situations. It was thus needed to explore whether incarcerated people with OUD were ready to try XR-BUP formulations, and which reasons could warrant their possible interest or apprehension.

Methods: This is a secondary analysis of a survey performed between 12/02/2018 and 05/31/2019 among 366 patients with OUD. Participants were recruited in 68 addiction French settings, among which six were prison medical centers. Bivariable and multivariable comparisons between incarcerated and nonincarcerated interviewees with respect to their readiness to try XR-BUP and the reasons of interest in this new option. Odds ratios and their $95 \%$ confidence intervals (aORs; $95 \% \mathrm{Cl}$ ) were adjusted for gender, age category, level of education, and type of opioid agonist treatment.

Results: The data of 317 participants were included in the analyses. While 108 (48.9\%) of the 221 nonincarcerated interviewees declared being ready to try XR-BUP, they were 63.5\% (61 out of 96) among those incarcerated $(p=0.016)$. Adjusted comparisons found that incarcerated were significantly less attracted by the potential of XR-BUP to reduce withdrawal symptoms (aOR= $0.54 ; 95 \% \mathrm{Cl}=0.29-0.99)$, and to reduce misuse of buprenorphine $(\mathrm{aOR}=0.56 ; 95 \% \mathrm{Cl}=0.34-0.94)$, but more attracted by receiving a constantly efficacious treatment for a week or month $(\mathrm{aOR}=2.91 ; 95 \% \mathrm{Cl}=1.21-6.98)$, and have a more discreet treatment $(\mathrm{aOR}=1.76 ; 95 \% \mathrm{Cl}=1.01-3.10)$.

Conclusions: Relative to non-incarcerated subjects with OUD, those in prison were readier to try XR-BUP and they seemed more attracted by practicability and discretion features.

\section{Introduction}

Methadone and buprenorphine are the most common types of opioid agonist treatments (OATs) used in the pharmacotherapy of opioid use disorder (OUD). OATs allow to substantially improve the outcomes of uncontrolled opioid use, and the global aspects of recovery and quality of life among OUD subjects [1]. However, OATs also have some specific drawbacks. Methadone may significantly increase the risks of overdose, in particular after initiation, and in case of insufficient supervision [2]. Sublingual buprenorphine can be diverted and misused through injection or intranasal use, which may lead to specific complications [3]. Furthermore, the current forms of buprenorphine and methadone require a daily intake, which may be a source of constraints, discomfort, oversight, or stigma [4].

For all these reasons, new galenic forms of extended-release buprenorphine (XR-BUP) have recently been developed and commercialized, offering a one-week, one-month, or six-month treatment coverage to OUD subjects, through subcutaneous depot or implant formulations [5]. These new treatment options 
essentially aim to improve treatment coverage, and thus, to improve efficacy by reducing withdrawal and craving, but also to improve comfort and convenience features among treatment-seeking OUD subjects. Surveys among people using opioids or treatment-seeking OUD subjects have revealed that these new galenic forms raise some interest for the reasons listed above. However, interviewees also raised some concerns, in particular in terms of coercive treatment and reduction in the ability to stop OAT and resume recreative opioid use, depending on individual preferences and treatment objectives [6-8].

OUD is frequent among incarcerated persons. Though no real prevalence rate has ever been estimated, it has been found that approximately one third of subjects with OUD is incarcerated annually [9]. For these subjects, incarceration can constitute an opportunity to initiate an OAT [10]. Compared with the incarcerated subjects with OUD who are untreated, those who receive an OAT show significant reductions in their overall opioid use during incarceration, as well as in their injection behaviors, prison infractions, and suicide and overall mortality risk in prison $[11,12]$. Moreover, the treated subjects are less likely to experience an overdose after prison release. Consequently, it has been deemed crucial to scale up OUD treatment and prevention strategies within a continuum of initiatives before, during, and after incarceration [12]. Despite this overall statement, the access to OATs remains globally insufficient in prison. The reasons are multiple and rely on a lack of resources and appropriate services, as well as on frequent negative representations among penitentiary and medical teams in prison, including stigma, uncertainty of the effectiveness of OATs, and apprehensions on safety issues, such as overdose, diversion, or misuse of OAT [13]. Barriers may also come from the prisoners' milieu, as OAT diversion is important in prison [14], which can lead to bullying and racket, and thus refrain inmates with OUD from seeking treatment [15].

Recent expert opinions and national guidelines have pointed out the interest of using XR-BUP in prison[4, 16], to better ensure treatment coverage, comfort, and discretion features, among the subjects who were willing to receive such new forms of OAT [4]. However, the surveys that have explored the interest for XRBUP among subjects with OUD have not included incarcerated subjects until now. It was thus unclear whether this specific population was interested in receiving XR-BUP formulations, and why. In a recent study conducted in France among 366 treatment-seeking subjects with OUD, approximately one third of the recruited sample consisted of incarcerated people. In this specific study, we thus aimed to compare between the incarcerated and non-incarcerated participants, the readiness to try an XR-BUP formulation, and the related factors of adherence.

\section{Materials And Methods}

The study is reported according to the 'Strengthening the reporting of observational studies in epidemiology' (STROBE) statement [17].

\section{Study Design and Population}


The 'AMBRE' study was a cross sectional survey conducted among 366 patients, recruited in 68 addiction French settings performing OAT prescriptions. Among them, 6 were prison medical centers. The survey took place between 12/02/2018 and 05/31/2019. Inclusion criteria were as follows: 1 ) being aged 18 years or more; 2 ) initiating or being currently treated with an OAT for OUD; 3 ) providing written consent for participating in the survey; and 4) being capable of completing a self-administered questionnaire.

\section{Study Questionnaire}

The questionnaire was built by the authors and pre-tested on small group of treatment-seeking OUD subjects, in order to ensure the acceptability and reproducibility of the collected data. The questionnaire aimed to explore: 1) the main sociodemographic features, clinical history, and characteristics of participants regarding their use of OAT;2) the participants' objectives with respect to their OUD treatment; and 3 ) the perceptions of participants regarding the convenient or problematic aspects of OAT in their daily life. Subsequently, after a quick presentation of what weekly and monthly XR-BUP consist of, participants were asked to score their potential interest in such a new galenic form of OAT, using a 1-10 Likert scale. A last series of questions explored the expectancies of participants regarding weekly and monthly XR-BUP. The complete blank questionnaire of the survey can be consulted in Supplemental

\section{Materials. \\ Statistical analyses}

In the present study, only the following items of the questionnaire were integrated in the analyses: 1) sociodemographic features of participants; 2 ) type of current OAT (i.e., buprenorphine or methadone); 3 ) readiness to try XR-BUP (yes vs. no, Q40); and 4) factors of adherence for XR-BUP (as investigated in Q28).

For simplifying the analysis process and the interpretation of the results, the responses to questions offering multiple answer options were binarized. The way how binary classes have been built can be found in Supplemental Table 1.

Categorical parameters are presented as the number of subjects and percentage $(n ; \%)$. Each variable of interest is presented for the entire sample, and compared between prison and non-prison participants, using bivariable tests. Comparisons were performed using chi-squared test or Fisher's exact test, when appropriate. Raw odds ratios and their $95 \%$ confidence interval (OR [95Cl\%]) are also displayed.

Subsequently, multivariable regression logistic regression models were built, with the responses to Q40 (readiness to try XR-BUP) and Q28 (adherence factors) as the dependent variables, prison vs. non-prison status as the explanatory variable, and sex, age category, level of education, and housing status, as adjustment variables, providing adjusted odds ratios and their $95 \%$ confidence interval (aOR [95Cl\%]).

Subjects with missing values were not integrated in the models. Statistical analyses were performed using the XLSTAT2019 software (https://www.xlstat.com/en/).

\section{Ethical aspects}


In accordance with the French law on clinical research (Loi Jardé), the study protocol was submitted to and approved by the CNIL (\#2211988).

\section{Results}

The main sociodemographic and clinical features of the total sample, and the responses to the readiness to try XR-BUP, and the related factors of adherence, are displayed in Table 1. This table also provides bivariable comparisons of the same parameters between incarcerated and non-incarcerated participants. 
Table 1

Influence of incarceration about OAT on the interest in XR-BUP

\begin{tabular}{|c|c|c|c|c|}
\hline Parameter & $\begin{array}{l}\text { Total } \\
\text { n (\%) }\end{array}$ & $\begin{array}{l}\text { Prisoner } \\
\text { n (\%) }\end{array}$ & $\begin{array}{l}\text { Not } \\
\text { incarcerated } \\
\text { n (\%) }\end{array}$ & p-value \\
\hline \multicolumn{5}{|l|}{ Gender } \\
\hline Male & $\begin{array}{l}239 \\
(75.4)\end{array}$ & $\begin{array}{l}86 \\
(36.0)\end{array}$ & $153(64.0)$ & \multirow[t]{2}{*}{$<0.001$} \\
\hline Female & $\begin{array}{l}78 \\
(24.6)\end{array}$ & $\begin{array}{l}10 \\
(12.8)\end{array}$ & $68(87.2)$ & \\
\hline \multicolumn{5}{|l|}{ Housing status } \\
\hline Unstable & $\begin{array}{l}96 \\
(30.3)\end{array}$ & $\begin{array}{l}61 \\
(63.5)\end{array}$ & $35(36.5)$ & \multirow[t]{2}{*}{$<0.001$} \\
\hline Stable & $\begin{array}{l}221 \\
(69.7)\end{array}$ & $\begin{array}{l}55 \\
(24.9)\end{array}$ & $166(75.1)$ & \\
\hline \multicolumn{5}{|l|}{ Level of education } \\
\hline Primary & $\begin{array}{l}27 \\
(8.5)\end{array}$ & $7(25.9)$ & $20(74.1)$ & \multirow[t]{3}{*}{0.005} \\
\hline Secondary & $\begin{array}{l}223 \\
(70.4)\end{array}$ & $\begin{array}{l}79 \\
(35.4)\end{array}$ & $144(64.6)$ & \\
\hline High school & $\begin{array}{l}67 \\
(21.1)\end{array}$ & $\begin{array}{l}10 \\
(14.9)\end{array}$ & $57(85.1)$ & \\
\hline \multicolumn{5}{|l|}{ Type of OAT } \\
\hline BUP or BUP/NAL & $\begin{array}{l}195 \\
(61.5)\end{array}$ & $\begin{array}{l}59 \\
(30.3)\end{array}$ & $136(69.7)$ & \multirow[t]{2}{*}{0.989} \\
\hline Methadone & $\begin{array}{l}122 \\
(38.5)\end{array}$ & $\begin{array}{l}37 \\
(30.3)\end{array}$ & $85(69.7)$ & \\
\hline \multicolumn{5}{|l|}{ Ready to try XR-BUP } \\
\hline No & $\begin{array}{l}148 \\
(46.7)\end{array}$ & $\begin{array}{l}35 \\
(23.6)\end{array}$ & $113(73.4)$ & 0.016 \\
\hline \multicolumn{5}{|l|}{ Abbreviations: } \\
\hline \multicolumn{5}{|l|}{ OAT: opioid agonist treatment } \\
\hline \multicolumn{5}{|l|}{ BUP: buprenorphine } \\
\hline \multicolumn{5}{|l|}{ BUP/NAL : buprenorphine/naloxone } \\
\hline XR-BUP: Extended-release buprenorphine & & & & \\
\hline
\end{tabular}




\begin{tabular}{|c|c|c|c|c|}
\hline Parameter & $\begin{array}{l}\text { Total } \\
\text { n (\%) }\end{array}$ & $\begin{array}{l}\text { Prisoner } \\
\text { n (\%) }\end{array}$ & $\begin{array}{l}\text { Not } \\
\text { incarcerated } \\
\text { n (\%) }\end{array}$ & $p$-value \\
\hline Yes & $\begin{array}{l}169 \\
(53.3)\end{array}$ & $\begin{array}{l}61 \\
(36.1)\end{array}$ & $108(63.9)$ & \\
\hline \multicolumn{5}{|l|}{ No longer having to take OAT every day } \\
\hline Not important & $\begin{array}{l}86 \\
(27.1)\end{array}$ & $\begin{array}{l}19 \\
(19.8)\end{array}$ & $77(80.2)$ & \multirow[t]{2}{*}{0.053} \\
\hline Important & $\begin{array}{l}231 \\
(72.9)\end{array}$ & $\begin{array}{l}67 \\
(30.3)\end{array}$ & $154(69.7)$ & \\
\hline \multicolumn{5}{|l|}{ No longer forgetting to take OAT } \\
\hline Not important & $\begin{array}{l}137 \\
(43.2)\end{array}$ & $\begin{array}{l}43 \\
(31.4)\end{array}$ & $94(68.6)$ & \multirow[t]{2}{*}{0.709} \\
\hline Important & $\begin{array}{l}180 \\
(56.8)\end{array}$ & $\begin{array}{l}53 \\
(29.4)\end{array}$ & $127(70.6)$ & \\
\hline \multicolumn{5}{|l|}{ Possibility to take OAT every week/month } \\
\hline Not important & $\begin{array}{l}63 \\
(19.9)\end{array}$ & $\begin{array}{l}17 \\
(27.0)\end{array}$ & $46(73.0)$ & \multirow[t]{2}{*}{0.524} \\
\hline Important & $\begin{array}{l}254 \\
(80.1)\end{array}$ & $\begin{array}{l}79 \\
(31.1)\end{array}$ & $175(68.9)$ & \\
\hline \multicolumn{5}{|l|}{$\begin{array}{l}\text { The fact that it is a subcutaneous (painless) } \\
\text { injection }\end{array}$} \\
\hline Not important & $\begin{array}{l}182 \\
(57.4)\end{array}$ & $\begin{array}{l}75 \\
(41.2)\end{array}$ & $107(58.8)$ & \multirow[t]{2}{*}{$<0.001$} \\
\hline Important & $\begin{array}{l}135 \\
(46.2)\end{array}$ & $\begin{array}{l}21 \\
(15.6)\end{array}$ & $114(84.6 .7)$ & \\
\hline \multicolumn{5}{|l|}{$\begin{array}{l}\text { Being sure to receive a constantly efficacious } \\
\text { treatment for a week/month }\end{array}$} \\
\hline Not important & $\begin{array}{l}44 \\
(13.9)\end{array}$ & $6(13.6)$ & $38(84.4)$ & 0.010 \\
\hline \multicolumn{5}{|l|}{ Abbreviations: } \\
\hline \multicolumn{5}{|l|}{ OAT: opioid agonist treatment } \\
\hline \multicolumn{5}{|l|}{ BUP: buprenorphine } \\
\hline \multicolumn{5}{|l|}{ BUP/NAL : buprenorphine/naloxone } \\
\hline XR-BUP: Extended-release buprenorphine & & & & \\
\hline
\end{tabular}




\begin{tabular}{|c|c|c|c|c|}
\hline Parameter & $\begin{array}{l}\text { Total } \\
\text { n (\%) }\end{array}$ & $\begin{array}{l}\text { Prisoner } \\
\text { n (\%) }\end{array}$ & $\begin{array}{l}\text { Not } \\
\text { incarcerated } \\
\text { n (\%) }\end{array}$ & $p$-value \\
\hline Important & $\begin{array}{l}273 \\
(86.1)\end{array}$ & $\begin{array}{l}90 \\
(33.0)\end{array}$ & $183(67.0)$ & \\
\hline \multicolumn{5}{|c|}{ Being more able to reduce/stop illicit opioid use } \\
\hline Not important & $\begin{array}{l}67 \\
(21.1)\end{array}$ & $\begin{array}{l}24 \\
(74.0)\end{array}$ & $43(26.0)$ & \multirow[t]{2}{*}{0.267} \\
\hline Important & $\begin{array}{l}250 \\
(78.9)\end{array}$ & $\begin{array}{l}72 \\
(28.8)\end{array}$ & $178(71.2 .0)$ & \\
\hline \multicolumn{5}{|c|}{ Being more able to avoid sharing/saling his/her OAT } \\
\hline Not important & $\begin{array}{l}179 \\
(56.5)\end{array}$ & $\begin{array}{l}60 \\
(33.5)\end{array}$ & $119(66.5)$ & \multirow[t]{2}{*}{0.153} \\
\hline Important & $\begin{array}{l}138 \\
(43.5)\end{array}$ & $\begin{array}{l}36 \\
(26.1)\end{array}$ & $102(73.9)$ & \\
\hline \multicolumn{5}{|l|}{ Reducing the risk of withdrawal } \\
\hline Not important & $\begin{array}{l}64 \\
(20.2)\end{array}$ & $\begin{array}{l}26 \\
(40.6)\end{array}$ & $38(59.4)$ & \multirow[t]{2}{*}{0.044} \\
\hline Important & $\begin{array}{l}253 \\
(79.8)\end{array}$ & $\begin{array}{l}70 \\
(27.7)\end{array}$ & $183[72.3)$ & \\
\hline \multicolumn{5}{|c|}{$\begin{array}{l}\text { Reducing the effects of heroin/morphine in case of } \\
\text { concurrent use }\end{array}$} \\
\hline Not important & $\begin{array}{l}148 \\
(46.7)\end{array}$ & $\begin{array}{l}53 \\
(35.8)\end{array}$ & $95(64.2)$ & \multirow[t]{2}{*}{0.045} \\
\hline Important & $\begin{array}{l}169 \\
(53.3)\end{array}$ & $\begin{array}{l}43 \\
(25.4)\end{array}$ & $126(74.6)$ & \\
\hline \multicolumn{5}{|c|}{$\begin{array}{l}\text { Reducing the need for injecting/snorting/smoking } \\
\text { his/her OAT }\end{array}$} \\
\hline Not important & $\begin{array}{l}163 \\
(51.4)\end{array}$ & $\begin{array}{l}58 \\
(35.6)\end{array}$ & $105(64.4)$ & 0.035 \\
\hline \multicolumn{5}{|l|}{ Abbreviations: } \\
\hline \multicolumn{5}{|l|}{ OAT: opioid agonist treatment } \\
\hline \multicolumn{5}{|l|}{ BUP: buprenorphine } \\
\hline \multicolumn{5}{|l|}{ BUP/NAL : buprenorphine/naloxone } \\
\hline XR-BUP: Extended-release buprenorphine & & & & \\
\hline
\end{tabular}




\begin{tabular}{|c|c|c|c|c|}
\hline Parameter & $\begin{array}{l}\text { Total } \\
\text { n (\%) }\end{array}$ & $\begin{array}{l}\text { Prisoner } \\
\mathrm{n}(\%)\end{array}$ & $\begin{array}{l}\text { Not } \\
\text { incarcerated } \\
\text { n (\%) }\end{array}$ & $p$-value \\
\hline Important & $\begin{array}{l}154 \\
(48.6)\end{array}$ & $\begin{array}{l}38 \\
(24.7)\end{array}$ & $116(75.3)$ & \\
\hline \multicolumn{5}{|c|}{ Having a more 'discreet' OAT, relative to oral forms } \\
\hline Not important & $\begin{array}{l}108 \\
(34.1)\end{array}$ & $\begin{array}{l}23 \\
(21.3)\end{array}$ & $85(78.7)$ & \multirow[t]{2}{*}{0.012} \\
\hline Important & $\begin{array}{l}209 \\
(66.9)\end{array}$ & $\begin{array}{l}73 \\
(34.9)\end{array}$ & $136(65.1)$ & \\
\hline \multicolumn{5}{|l|}{ Reduced constraints } \\
\hline Not important & $\begin{array}{l}76 \\
(24.0)\end{array}$ & $\begin{array}{l}18 \\
(23.7)\end{array}$ & $58(76.3)$ & \multirow[t]{2}{*}{0.151} \\
\hline Important & $\begin{array}{l}241 \\
(76.0)\end{array}$ & $\begin{array}{l}78 \\
(32.4)\end{array}$ & $163(67.6)$ & \\
\hline \multicolumn{5}{|l|}{ Abbreviations: } \\
\hline \multicolumn{5}{|l|}{ OAT: opioid agonist treatment } \\
\hline \multicolumn{5}{|l|}{ BUP: buprenorphine } \\
\hline \multicolumn{5}{|l|}{ BUP/NAL : buprenorphine/naloxone } \\
\hline XR-BUP: Extended-release buprenorphine & & & & \\
\hline
\end{tabular}

Table 2 displays the raw ORs and aORs, and their $95 \% \mathrm{Cl}$, with respect to the comparisons in the different parameters between incarcerated and non-incarcerated participants, before and after adjusting for gender, age category, level of education, and type of OAT. Overall, multivariable comparisons found that, relative to non-incarcerated participants, incarcerated participants were readier to try XR-BUP $(a O R=1.80$; $95 \% \mathrm{Cl}=1.04$ to 3.13 ). Increased factors of adherence for these new formulations were receiving a constantly-efficacious treatment for a week or one month $(\mathrm{aOR}=2.91 ; 95 \% \mathrm{Cl}=1.21$ to 6.98$)$, and having a more discreet form of OAT, compared to oral forms $(\mathrm{aOR}=1.76 ; 95 \% \mathrm{Cl}=1.01$ to 3.10$)$. By contrast, incarcerated subjects granted significantly less interest in the fact that the subcutaneous injection was painless $(\mathrm{aOR}=0.24 ; 95 \% \mathrm{Cl}=0.14$ to to 0.43$)$, or that XB-BUP could reduce the risk of withdrawal $(\mathrm{aOR}=$ $0.54 ; 95 \% \mathrm{Cl}=0.29$ to 0.99$)$, or reduce the need for injecting, snorting their OAT $(\mathrm{aOR}=0.56 ; 95 \% \mathrm{Cl}=0.34$ to 0.94 ). 
Table 2

Raw and adjusted comparisons of readiness to try XR-BUP and factors of adherence between incarcerated and non-incarcerated subjects

$\begin{array}{lll}\text { Parameter } & \text { OR }[95 \% \mathrm{Cl}] & \text { aOR }[95 \% \mathrm{Cl}]^{\text {a }}\end{array}$

Ready to try XR-BUP

Incarcerated $(n=96 ; 29.9 \%)$

$1.74[1.03-$

$2.96]^{*}$

$1.80[1.04-$

$3.13]^{*}$

Not incarcerated $(n=225 ; 70.1 \%)$

1

1

Factors of adherence for XR-BUP

No longer taking OAT every day $(n m v=2)$

Incarcerated $(n=96 ; 30.1 \%)$

$1.76[0.99-$

$1.81[0.99-$

$3.14] \dagger$

3.31] †

Not incarcerated $(n=223 ; 69.9 \%)$

1

1

No longer forgetting to take OAT $(\mathrm{nmv}=5)$

Incarcerated $(n=96 ; 30.4 \%)$

$0.91[0.56-$

1.48]

$0.87[0.52-$

1.44]

Not incarcerated ( $n=220 ; 69.6 \%)$

1

1

Taking the OAT every week/month $(n m v=6)$

Incarcerated $(n=95 ; 30.2 \%)$

$1.22[0.66-$

2.26]

$1.25[0.65-2.4]$

Not incarcerated $(n=220 ; 69.8 \%)$

1

1

Having a subcutaneous painless injection $(n m v=3)$

Incarcerated $(n=96 ; 30.2 \%)$

$0.26[0.15-$

$0.46] * \star \star$

$0.24[0.14-$

$0.43]^{* * *}$

Not incarcerated $(n=222 ; 69.8 \%)$

1

\section{Receiving a constantly efficacious treatment for a} week/month $(\mathrm{nmv}=3)$

Incarcerated $(n=96 ; 30.2 \%)$

$3.11[1.27-$

$7.64]^{*}$

$2.91[1.21-$

$6.98]^{*}$

Not incarcerated $(n=222 ; 69.8 \%)$

1

Being more able to reduce/stop illicit opioid use $(n m v=3)$

Incarcerated $(n=96 ; 30.2 \%)$

$0.72[0.41-$

1.28]

$0.67[0.36-$ $1.24]$

Not incarcerated $(n=222 ; 69.8 \%)$

1 


\section{Parameter}

OR $[95 \% \mathrm{Cl}]$

aOR $[95 \% \mathrm{Cl}]^{\mathrm{a}}$

Being able to avoid sharing/selling his/her OAT $(n m v=4)$

Incarcerated $(n=96 ; 30.3 \%)$

$0.70[0.43-$

$1.14]$

$0.70[0.42-$

Not incarcerated $(n=221 ; 69.7 \%)$

1

1.17]

Not incarcerated $(n=221 ; 69.7 \%)$

1

Reducing the risk of withdrawal $(\mathrm{nmv}=5)$

Incarcerated $(n=96 ; 30.4 \%)$
$0.56[0.32-$
$0.99]$ *
$0.54[0.29-$
$0.99]^{*}$

Not incarcerated $(n=220 ; 69.6 \%)$

1

1

\section{Reducing the effect of heroin/morphine in case of concurrent}

use $(\mathrm{nmv}=10)$

Incarcerated $(n=93 ; 29.9 \%)$

$0.61[0.38-$

$0.62[0.37-$

$0.99]$ *

$1.03] \dagger$

Not incarcerated $(n=218 ; 70.1 \%)$

1

1

Reducing the need for injecting/snorting/smoking his/her OAT $(\mathrm{nmv}=6)$

Incarcerated $(n=96 ; 30.5 \%)$

$0.59[0.36-$

$0.96]$ *

$0.56[0.34-$

$0.94]^{*}$

Not incarcerated $(n=219 ; 69.5 \%)$

1

1

Having a more discreet OAT vs oral form $(n m v=4)$

Incarcerated $(\mathrm{n}=96 ; 30.3 \%)$

$1.98[1.15-$

$3.41]$ *

$1.76[1.01-$

$3.10]$ *

Not incarcerated $(n=221 ; 69.7 \%)$

1

1

Reducing the constraints related to OAT $(n m v=3)$

Incarcerated $(\mathrm{n}=96 ; 30.2 \%)$

$1.54[0.85-$

2.79]

$1.44[0.78-$

Not incarcerated $(n=222 ; 69.8$

Not incarcerated $(n=222 ; 69.8 \%)$

1

2.68]

Improving treatment compliance / reducing relapse $(\mathrm{nmv}=3)$

Incarcerated $(n=96 ; 30.3 \%)$

$1.29[0.75-$

2.21]

$1.42[0.81-$

2.47]

Not incarcerated $(n=221 ; 69.7 \%)$

1

1

$+\mathrm{p}<0.1$

* $p<0.05$ 


\begin{tabular}{|l|}
\hline Parameter $\quad$ OR [95\% Cl] aOR [95\% $\mathrm{Cl}^{\mathrm{a}}{ }^{\mathrm{a}}$ \\
\hline$* \star \mathrm{p}<0.001$ \\
\hline$* \star * \mathrm{p}<0.0001$ \\
\hline Abbreviations: \\
\hline OR: odds ratio \\
\hline aOR: adjusted OR \\
\hline (a adjusted for gender, age category, level of education, and type of OAT) \\
\hline 95\%Cl: $95 \%$ confidence interval \\
\hline nmv: number of missing values \\
\hline OAT: opioid agonist treatment \\
\hline BUP: buprenorphine \\
\hline XR-BUP: Extended-release buprenorphine \\
\hline
\end{tabular}

\section{Discussion}

The objective of the study was to compare the readiness to try XR-BUP among incarcerated subjects, relative to the non-incarcerated participants of the survey. Previous analyses found that a majority of the participants of this survey were interested in the principle of XR-BUP [18]. Both expert opinions and national guidelines have pointed out that XR-BUP formulations could be of particular interest in prisons, in particular for both convenience and efficacy reasons $[4,16]$. However, because the concept of XR-BUP has raised concerns in some opioid users, with respect to a possible limitation of freedom and coercive treatment $[6,7]$, it was thus particularly important to address whether incarcerated people with OUD were ready to try XR-BUP, or, by contrast, reluctant to receive it.

First, almost two thirds of this population declared being ready to try an XR-BUP formulation, vs. barely more than $50 \%$ of participants in the non-incarcerated group (Table 1). This first finding thus offers encouraging prospects for proposing this treatment option to OUD subjects in prisons. Moreover, this result is in line with a similar survey in which incarcerated subjects were interviewed with respect to their readiness to try extended-release naltrexone injection [19]. Naltrexone injection conveys similar apprehensions than XR-BUP among opioid users, as it is associated with the need of a complete and sustained cessation of opioid use, and with a likelihood of withdrawal [20], a majority of the incarcerated subjects interviewed in this survey also considered extended release naltrexone injection as an appropriate treatment option for their OUD. 
A second finding of our survey was that, despite being readier to try XR-BUP, incarcerated interviewees were less attracted by improving the effectiveness of the treatment. For example, they were significantly less interested in no longer experiencing withdrawal, or misusing their OAT, and they were not more interested in a treatment that could help them improving compliance or reducing relapse. By contrast, they seemed more attracted by practicability aspects, for example by no longer having to take their OAT every day, or receiving a more discreet treatment. As buprenorphine diversion and misuse are widespread in prison [14], drug-related traffic can be an important source of bullying and violence in these settings [21]. Consequently, the subjects with OUD that receive a sublingual formulation of buprenorphine in prison can be more exposed to harassment and extortion than those receiving a depot or implant form. This may explain the patterns of responses found in the survey, although this would require further investigation.

This survey had some limitations that should be acknowledged. First, the study population was a convenient sample. Because these types of survey investigate people with illegal behaviors, it is usually very hard to build a "representative" sample with these populations with OUD. Nevertheless, the sample of the survey was in line with several features of French people with OUD, including the proportion of males vs. females, or the proportion of subjects treated with buprenorphine or methadone [18]. A similar limitation was that the groups compared were not paired, which could have generated biases, even if multivariable comparisons were adjusted on important sociodemographic and clinical features. A last limitation was that, because XR-BUP formulations are not commercialized yet in France, this survey explored the intentions and representations of subjects who had no practical experience of the product. Results may thus be very similar if a comparable study is performed after marketing of XR-BUP formulations.

Despite these limitations, our findings suggest that a majority of people with OUD in prisons will not be particularly reluctant for receiving XR-BUP formulations, and that their main motivations for trying this new option rely on discretion and practicability aspects, and not really on efficacy or safety features.

\section{Declarations}

Ethics approval and consent to participate: the study protocol was approved by the CNIL (\#2211988).

Consent for publication: not applicable

Availability of data and materials: The datasets used and/or analysed during the current study are available from the corresponding author on reasonable request.

Competing interests: BR received fees for lectures and consultancy from Camurus, Individor, Recordati, and Ethypharm. BT received fees for consultancy from Camurus. JB received fees for lectures or consultancy from Camurus, Indivior, Bouchara and Shire. MK and PH are employed by Camurus, France, and Camurus, Sweden, respectively. FM received fees for lectures or consultancy from Camurus and 
Indivior. PN received fees for lectures or consultancy from Camurus. GB received fees for lectures or consultancy from Camurus and Indivior. Other authors declare having no conflict of interest.

Funding: This study was sponsored by Camurus. Camurus contributed to the study design and analysis Plan. Camurus played no role in collection, and analysis of the manuscript. PH and MK (from Camurus) participated in the discussion and interpretation of the results.

Authors' contributions: $\mathrm{GB}, \mathrm{BT}, \mathrm{JB}, \mathrm{PN}, \mathrm{PH}$, and MK designed the study. $\mathrm{BR}, \mathrm{BT}, \mathrm{MC}, \mathrm{PB}, \mathrm{FM}, \mathrm{JB}, \mathrm{PN}$ and $\mathrm{GB}$ recruited participants. $B R$ and $M C$ analyzed the data. $B R$ and $M C$ wrote the first draft of the manuscript. All authors read and approved the final draft.

Acknowledgements: The authors thank the survey participants, as well as the investigators who recruited them. They also thank the "KAPPA Santé" team, the CRO which implemented the study and collected the data.

\section{Abbreviations}

XR-BUP: extended-release buprenorphine

OUD: opioid use disorder

OATs: opioid agonist treatments

\section{References}

1. Bell J, Strang J. Medication Treatment of Opioid Use Disorder. Biol Psychiatry. 2020;87(1):82-8. doi:10.1016/j.biopsych.2019.06.020.

2. Sordo L, Barrio G, Bravo MJ, Indave BI, Degenhardt L, Wiessing L, Ferri M, Pastor-Barriuso R. Mortality risk during and after opioid substitution treatment: systematic review and meta-analysis of cohort studies. BMJ 2017 Apr 26;357:j1550. PMID:28446428.

3. Strang J, Volkow ND, Degenhardt L, et al. Opioid use disorder. Nat Rev Dis Primers. 2020;6(1):3. doi:10.1038/s41572-019-0137-5. Published 2020 Jan 9.

4. Vorspan F, Hjelmström P, Simon N, et al. What place for prolonged-release buprenorphine depotformulation Buvidal ${ }^{\circledR}$ in the treatment arsenal of opioid dependence? Insights from the French experience on buprenorphine. Expert Opin Drug Deliv. 2019;16(9):907-14.

doi:10.1080/17425247.2019.1649252.

5. Chappuy M, Trojak B, Nubukpo P, et al. Prolonged-release buprenorphine formulations: Perspectives for clinical practice [published online ahead of print, 2020 May 18]. Therapie. 2020;S00405957(20):30096-2. doi:10.1016/j.therap.2020.05.007.

6. Tompkins CNE, Neale J, Strang J. Opioid users' willingness to receive prolonged-release buprenorphine depot injections for opioid use disorder. J Subst Abuse Treat. 2019;104:64-71. 
doi:10.1016/j.jsat.2019.06.007.

7. 10.1016/j.drugalcdep.2018.03.057]

Neale J, Tompkins CNE, McDonald R, Strang J. Implants and depot injections for treating opioid dependence: Qualitative study of people who use or have used heroin. Drug Alcohol Depend [Internet] Elsevier Ireland Ltd; 2018 Aug 1 [cited 2020 Mar 19];189:1-7. [doi:

10.1016/j.drugalcdep.2018.03.057].

8. Larance B, Degenhardt L, Grebely J, et al. Perceptions of extended-release buprenorphine injections for opioid use disorder among people who regularly use opioids in Australia. Addiction. 2020;115(7):1295-305. doi:10.1111/add.14941.

9. Boutwell AE, Nijhawan A, Zaller N, Rich JD. Arrested on heroin: a national opportunity. J Opioid Manag. 2007;3(6):328-32. doi:10.5055/jom.2007.0021.

10. Moore KE, Roberts W, Reid HH, Smith KMZ, Oberleitner LMS, McKee SA. Effectiveness of medication assisted treatment for opioid use in prison and jail settings: A meta-analysis and systematic review. J Subst Abuse Treat. 2019;99:32-43. doi:10.1016/j.jsat.2018.12.003.

11. Degenhardt L, Grebely J, Stone J, et al. Global patterns of opioid use and dependence: harms to populations, interventions, and future action. Lancet. 2019;394(10208):1560-79.

doi:10.1016/S0140-6736(19)32229-9.

12. Malta $M$, Varatharajan T, Russell $C$, Pang $M$, Bonato S, Fischer B. Opioid-related treatment, interventions, and outcomes among incarcerated persons: A systematic review. PLoS Med Public Library of Science; 2019;16(12). [doi: 10.1371/journal.pmed.1003002].

13. Brezel ER, Powell T, Fox AD. An ethical analysis of medication treatment for opioid use disorder (MOUD) for persons who are incarcerated. Subst Abus. 2020;41(2):150-4. doi:10.1080/08897077.2019.1695706.

14. Bi-Mohammed Z, Wright NM, Hearty P, King N, Gavin H. Prescription opioid abuse in prison settings: A systematic review of prevalence, practice and treatment responses. Drug Alcohol Depend. 2017;171:122-31. doi:10.1016/j.drugalcdep.2016.11.032.

15. Tompkins CNE, Wright NMJ, Waterman MG, Sheard L. Exploring prison buprenorphine misuse in the United Kingdom: A qualitative study of former prisoners. Int J Prison Health 2009 Jun;5(2):71-87. [doi: 10.1080/17449200902880482].

16. National Institute for Health and Care Excellence. Key messages | Opioid dependence: buprenorphine prolonged-release injection (Buvidal) | Advice | NICE [Internet]. Evid Summ [ES19]. NICE; 2019 [cited 2020 Jun 27]. Available from: https://www.nice.org.uk/advice/es19/chapter/Key-messages.

17. von Elm E, Altman DG, Egger M, Pocock SJ, Gøtzsche PC, Vandenbroucke JP. Strengthening the Reporting of Observational Studies in Epidemiology (STROBE) statement: guidelines for reporting observational studies. BMJ [Internet]. 2007;335(7624):806-8. cited 2015 Dec 6 ;(. PMID:17947786.

18. Rolland B, Trojak B, Nourredine M, Bachellier J, Chappuy M, Bendimerad P, Kosim M, Hjelmström P, Meroueh F, Nubukpo P, Brousse G. Determinants of interest in extended-released buprenorphine: a 
survey among 366 French subjects treated with buprenorphine or methadone. Drug Alcohol Depend 2020; In revision.

19. Murphy PN, Mohammed F, Wareing M, et al. High drug related mortality rates following prison release: Assessing the acceptance likelihood of a naltrexone injection and related concerns. J Subst Abuse Treat. 2018;92:91-8. doi:10.1016/j.jsat.2018.07.002.

20. Bahji A, Carlone D, Altomare J. Acceptability and efficacy of naltrexone for criminal justice-involved individuals with opioid use disorder: a systematic review and meta-analysis. Addiction. 2020;115(8):1413-25. doi:10.1111/add.14946.

21. Crewe B. Prisoner society in the era of hard drugs. Punishment Society. 2005;7(4):457-81. https://doi.org/10.1177/1462474505057122.

\section{Supplementary Files}

This is a list of supplementary files associated with this preprint. Click to download.

- SupplementalTable.docx

- renamed97291.docx 